\title{
SNS-032 prevents hypoxia-mediated glioblastoma cell invasion by inhibiting hypoxia inducible factor-1 $\alpha$ expression
}

\author{
M. AKTAR ALI ${ }^{1}$, AIMEE REIS ${ }^{1}$, LIANG-HAO DING ${ }^{1}$, MICHAEL D. STORY $^{1 *}$, AMYN A. HABIB ${ }^{2 *}$, \\ ANSUMAN CHATTOPADHYAY ${ }^{3}$ and DEBABRATA SAHA ${ }^{1 *}$ \\ Departments of ${ }^{1}$ Radiation Oncology, Division of Molecular Radiation Biology and ${ }^{2}$ Neurology, \\ University of Texas Southwestern Medical Center, ${ }^{*}$ Simmons Comprehensive Cancer Center, 2201 Inwood Road, \\ Dallas, TX 75390-9187; ${ }^{3}$ Health Sciences Library System, University of Pittsburgh, PA, USA
}

Received December 8, 2008; Accepted January 29, 2009

DOI: 10.3892/ijo_00000231

\begin{abstract}
Hypoxia and hypoxia inducible factor-1 $\alpha$ (HIF-1 $\alpha$ ) play a critical role in glioblastoma (GBM) which is characterized by highly aggressive and widespread cell invasion into adjacent normal brain tissue. The purpose of this study was to investigate the effect of the novel aminothiazole compound SNS-032 in glioblastoma cell invasion under hypoxic condition. SNS-032 is a potent and selective inhibitor of cyclin-dependent kinases 2, 7 and 9 and inhibits both cell cycle and transcription. We analyzed the effect of SNS-032 $(0.5 \mu \mathrm{M})$ on HIF- $1 \alpha$ expression and its major trans-regulating factors including COX-2, VEGF, MMP-2 and uPAR that are involved in cellular invasion in tumor hypoxia. Our observations demonstrate SNS-032: i) inhibited hypoxia-induced U87MG cell invasion and among all the other inhibitors tested, SNS-032 is the most effective, ii) blocked HIF-1 $\alpha$ mediated transcription of COX-2, MMP-2, VEGF and UPAR expression in U87MG cells in response to hypoxia, iii) blocked HIF- $1 \alpha$ expression by a proteasome independent pathway. The effects were similar to those observed with HIF- $1 \alpha$ siRNA which prevented cellular invasion by blocking HIF-1 $\alpha$ expression and its downstream effectors. Taken together, our data suggest that SNS-032 prevents hypoxia-mediated U87MG
\end{abstract}

Correspondence to: Dr Debabrata Saha, Department of Radiation Oncology, Division of Molecular Radiation Biology, University of Texas Southwestern Medical Center, 2201 Inwood Road, Dallas, TX 75390-9187, USA

E-mail: debabrata.saha@utsouthwestern.edu

Abbreviations: CDK, cyclin-dependent kinase; COX-2, cyclooxygenase 2; ECM, extracellular matrix; HIF-1, hypoxia inducible factor-1; MMP-2, matrix metalloproteinase 2; uPAR, urokinasetype plasminogen activator receptor; VEGF, vascular endothelial growth factor

Key words: hypoxia, cell invasion, HIF-1 $\alpha$, CDK, VEGF, MMPs, SNS-032, VEGF, glioblastoma cell invasion by blocking the expression of HIF-1 $\alpha$ and its trans-regulating factors. Our results present an opportunity in controlling highly invasive tumors such as glioblastoma using this novel class of compounds.

\section{Introduction}

Despite aggressive treatment strategy and technological development, glioblastoma multiforme (GBM) has remained difficult to treat. The overall response to the current standard of care for the treatment of GBM has been essentially poor. One of the main reasons that the GBM is practically incurable is the diffuse nature of the disease infiltrating into the surrounding normal brain tissues (1-7). As a result of this complex character complete eradication of the malignant tumor either by surgery or radiotherapy is impossible. Significant progress has been made to uncover mechanisms of this type of aggressive invasion of glioma cells that will help to find new treatment strategies that are urgently needed.

GBM characteristically contain extensive areas of hypoxia (low oxygen tension), which is a powerful stimulus for the expression of genes involved in aggressive proliferation, invasion, and angiogenesis (1). The transcription factor hypoxia-inducible factor-1 (HIF-1) is one of the master regulators which regulate more than 100 genes (8) allowing cells not only to adapt to hypoxic microenviroment but also induces transcription of its target genes which play an imperative role in invasion and angiogenesis. The $\alpha$ subunit of HIF-1 is stable in hypoxic conditions but is rapidly degraded in normoxia by an oxygen dependent ubiquitination-proteasome pathway. Hypoxic activation of the HIF-1 pathway is a common feature of gliomas and may explain the intense vascular hyperplasia and aggressive invasion often seen in GBM. Hypoxic activation of HIF- $1 \alpha$ results in the activation of COX-2 (9,10), VEGF (8), VEGFR (11), MMPs $(12,13)$, uPA and UPAR (14) responsible for increased glioma cell invasion and angiogenesis.

Invasion of glioma cell involves the attachment of invading tumor cells to extracellular matrix (ECM), disruption of ECM components, and subsequent cell penetration into adjacent brain structures. This is accomplished in part by matrix metalloproteases (MMPs) that degrade the ECM $(15,16)$. 
Up-regulation of MMP-2, a member of the MMP family, has been found in glioma cell lines and in high-grade glioma specimens (17). The enzyme serine proteases especially urokinase-type plasminogen activator (uPA) and its receptor uPAR are also often expressed at high levels in malignant brain tumors (18). A large body of evidence suggests that uPA plays a key role in tumor progression and invasion by virtue of its ability to activate plasminogen, which degrades many ECM components and activates latent collagenases (14). Hypoxia upregulated HIF-1 $\alpha$ binds directly to the $C O X-2$ promoter, thereby increasing $\mathrm{COX}-2$ transcription and protein synthesis. $\mathrm{COX}-2$ and $\mathrm{PGE}_{2}$ contribute to invasiveness and angiogenesis of tumors through activation of several matrix metalloproteinases (MMPs) $(19,20)$ and growth factors and their receptors $(21,22)$. VEGF known to be transcriptionally upregulated by HIF- $1 \alpha$, plays a key role in tumor growth, angiogenesis and invasion $(23,24)$. VEGF upregulates the expression of the chemokine receptor CXCR4 which mediates migration and invasion of tumor cells by stromalderived factor- 1 and this migration is dependent on the autocrine loop of VEGF (25).

Cyclin-dependent kinases (CDKs) play a critical role in cancer progression $(26,27)$. Several CDK inhibitors such as flavopiridol, UCN-01, CYC202, and SNS-032 (formerly known as BMS-387032) are undergoing clinical evaluation (28). The major purpose of this study is to investigate the role of a novel CDK inhibitor in the prevention of glioblastoma cell invasion. Newer generation of CDK antagonists such as SNS-032 are more selective and less toxic (27). However, it is not known whether this improved selectivity retains the anti-invasive or anti-angiogenic property shown by this class of inhibitors. Therefore, it is essential to obtain a clear understanding of whether selective inhibition of a small cohort of CDKs impacts tumor invasiveness and angiogenesis. In our recent report, we demonstrated that SNS-032 strongly prevents glioblastoma cell-induced angiogenesis by inhibiting VEGF expression (23).

In this study we have demonstrated that HIF-1 $\alpha$ is a key component in glioma cell invasion. We show that SNS-032, a selective inhibitor of CDK 2, 7 and 9, blocked HIF-1 $\alpha$ and its transcriptional products COX-2, MMP-2, VEGF, uPAR leading to a marked inhibition of hypoxia-mediated glioma cell invasion. Our findings thus suggest SNS-032 is a potential therapeutic agent in preventing the invasion of glioma cells.

\section{Materials and methods}

Materials. Cyclin-dependent kinase inhibitor SNS-032 was obtained from Sunesis (Sunesis Pharmaceuticals, Inc., South San Francisco, CA). A 10-mM stock solution was prepared in distilled water and stored at $-20^{\circ} \mathrm{C}$. Penicillin-streptomycin, Dulbecco's modified Eagle's medium (DMEM), fetal bovine serum (FBS), L-glutamine and Lipofectamine 2000 were purchased from Invitrogen (Grand Island, NY, USA). BD Biocoat Matrigel Invasion Chamber was purchased from BD Biosciences Discovery Labware (Bedford, MA). Following antibodies were used in this study; COX-2 monoclonal antibody (Cayman Chemical, Ann Arbor, MI, USA), mouse antiHIF-1 $\alpha$ (BD Transduction Laboratories, San Jose, CA), actin antibodies (Sigma-Aldrich Co., St. Louis, MO, USA). The
26S Proteasome inhibitor MG132 (Biomol, Plymouth Meeting, PA, USA) was dissolved in dimethyl sulfoxide and stock solution $(5 \mathrm{mM})$ was stored at $-20^{\circ} \mathrm{C}$. MMP inhibitor GM6001 was purchased from Chemicon International (Temecula, CA) and VEGFR inhibitor SU5416 was purchased from Calbiochem.

Cell culture. The human glioblastoma cell line U87MG was purchased from the American Type Culture Collection (HTB-14, Manassas, VA). Cells were cultured in 5\% $\mathrm{CO}_{2}$ and $95 \%$ humidified atmosphere air at $37^{\circ} \mathrm{C}$ in Dulbecco's modified Eagle's medium (DMEM) supplemented with $10 \%$ FBS, $1 \%$ penicillin and streptomycin, $2 \mathrm{mM}$ glutamine and $25 \mathrm{mM}$ HEPES. U87MG cells were split every 3 days to ensure logarithmic growth. For hypoxic exposure, cells were placed in a sealed Modular Incubator Chamber (BillupsRothenberg, Inc., Del Mar, CA) flushed with a gas mixture containing $1 \% \mathrm{O}_{2}, 5 \% \mathrm{CO}_{2}$ and $94 \% \mathrm{~N}_{2}$.

In vitro invasion assay. Invasion of cells through Matrigel was determined using 24-well BD invasion chambers $(8.0-\mu \mathrm{m}$ pore size with polyethylene tetraphthalate membrane). Invasion chambers were re-hydrated with serum-free DMEM (500 $\mu \mathrm{l} /$ well) for $2 \mathrm{~h}$. After trypsinization, U87MG cells were suspended in serum-free DMEM $(500 \mu 1)$ at a concentration of $5 \times 10^{4}$ cells/well and immediately placed onto the upper compartment of the plates. Subsequently, the lower compartment was filled with complete medium $(750 \mu 1)$. Cells were allowed to adhere for $2 \mathrm{~h}$ in normoxic $\left(20 \% \mathrm{O}_{2}\right)$ conditions. After complete attachment, the invasion chambers were incubated for 24 and $48 \mathrm{~h}$ in normoxic $\left(20 \% \mathrm{O}_{2}\right)$ or hypoxic $\left(1 \% \mathrm{O}_{2}\right)$ conditions at $37^{\circ} \mathrm{C}$ with or without SNS-032 $(0.5 \mu \mathrm{M})$. Following incubation, inserts were fixed in absolute methanol for $2 \mathrm{~min}$ at room temperature and stained with $1 \%$ toluidine blue in $1 \%$ borax for $3 \mathrm{~min}$. The cells on the upper surface of the insert were removed using a cotton-tipped swab. Images of randomly selected fields (minimum of 10 fields) were taken using a Nikon camera connected to an inverted microscope (final magnification x100, Olympus). Each assay was performed in duplicate and repeated three times. The data collected from independent experiments were pooled for statistical analysis.

Western blot analysis. Glioblastoma (U87MG) cells $\left(2 \times 10^{6}\right)$ were pre-incubated with $0.5 \mu \mathrm{M} \mathrm{SNS}-032$ for $2 \mathrm{~h}$ and exposed to $20 \% \mathrm{O}_{2}$ or $1 \% \mathrm{O}_{2}$ for 24 and $48 \mathrm{~h}$. After incubation cells were removed quickly from the hypoxic chamber, harvested and lysed using ice-cold RIPA buffer $(150 \mathrm{mM} \mathrm{NaCl}, 1 \%$ Nonidet P-40, $1 \%$ deoxycholate, $0.1 \%$ SDS, $10 \mathrm{mM}$ Tris- $\mathrm{HCl}$, $\mathrm{pH}$ 8.0, 1 mM EDTA, pH 8.0) supplemented with protease inhibitor cocktail (Sigma-Aldrich, St. Louis, MO). Forty $\mu \mathrm{g}$ of total protein was subjected to $7.5 \%$ SDS-PAGE and transferred to PVDF membranes (Bio-Rad, Bedford, MA). The membranes were blocked for $1 \mathrm{~h}$ with $5 \%$ non-fat dry milk in TBS-T (10 mM Tris-HCl, pH 7.6, and $150 \mathrm{mM} \mathrm{NaCl}$, $0.1 \%$ Tween-20) and incubated with primary antibodies in $5 \%$ milk at $4{ }^{\circ} \mathrm{C}$ overnight. The membranes were washed with TBS-T and incubated for $2 \mathrm{~h}$ at room temperature with HRP-conjugated secondary antibodies. The same membrane was re-probed with anti- $\beta$-actin antibodies (at 1:2000 dilution) 
Table I. PCR primers used for real-time-PCR.

\begin{tabular}{lll}
\hline Gene & & Sequence $\left(5^{\prime} \rightarrow 3^{\prime}\right)$ \\
\hline COX-2 & Sense: & GCGGGAACACAACAGAGTATGC \\
& Anti-sense: & CAGCATAAAGCGTTTGCGGTACT \\
VEGF & Sense: & CGAAGTGGTGAAGTTCATGGATG \\
& Anti-sense: & TTCTGTATCAGTCTTTCCTGGT \\
MMP-2 & Sense: & CTGATAACCTGGATGCTGTCGT \\
uPAR & Anti-sense: & GATGCTTCCAAACTTCACGCT \\
& Sense: & AACGACACCTTCCACTTC \\
B-actin & Anti-sense: & TTGCAGCTGTAACACTGG \\
& & \\
& Sense: & GTACCACTGGCATCGTGATGGACT \\
& Anti-sense: & ATCCACACGGAGTACTTGCGCTCA \\
\hline
\end{tabular}

and provided as loading control. Membranes were developed by the enhanced chemiluminescence system (Amersham Pharmacia Biotech, Piscataway, NJ) and exposed to Hyperfilm (Amersham Pharmacia Biotech).

Real-time RT-PCR. Quantitative RT-PCR was carried out with SYBR Green PCR master mix using the SYBR Green 1 dye (Applied Biosystems, Foster City, CA). After required treatment and indicated time of incubation, cells were washed in PBS and total RNA were isolated using TRIzol (Invitrogen, Carlsbad, CA). RNA was subsequently reverse transcribed to cDNA with the SuperScript First-strand Synthesis System followed by quantitative RT-PCR. Primer (Invitrogen) concentrations $(0.4 \mu \mathrm{M})$ were optimized before use. Sequence of all primers used in this study mentioned in Table I. SYBR Green PCR master kit was used with the appropriate concentrations of forward and reverse primers in a total volume of $20 \mu \mathrm{l}$. PCR reactions contained $1 \mu \mathrm{l}$ cDNA. Optimization was performed for each gene-specific primer confirming $0.4 \mu \mathrm{M}$ primer concentrations did not produce non-specific primer-dimer amplification in no-template control wells. Quantitative RT-PCR was carried (PTC-200, MJ Research, Ramsey, MN) with the three-stage program parameters as follows: $2 \mathrm{~min}$ at $50^{\circ} \mathrm{C}, 10 \mathrm{~min}$ at $95^{\circ} \mathrm{C}$, and then 40 cycles of $15 \mathrm{sec}$ at $95^{\circ} \mathrm{C}$ and $1 \mathrm{~min}$ at $60^{\circ} \mathrm{C}$. Specificity of the produced amplification product was confirmed by examination of dissociation reaction plots. A distinct single peak indicated that a single DNA sequence was amplified during RT-PCR. Each sample was tested in triplicate with quantitative RT-PCR, and samples obtained from three independent experiments were used for analysis of relative gene expression. The sequence of the primers used for realtime PCR is shown in Table I. B-actin was used as the internal control for each experiment.

siRNA transfection. In a 60-mm culture dish, U87MG cells were transiently transfected with human HIF-1 $\alpha$ siRNA and a negative control siRNA using Lipofectamine 2000. Cells were rinsed with PBS after $8 \mathrm{~h}$ of transfection, complete medium was added and further incubated for $40 \mathrm{~h}$. Cells were then exposed to hypoxia or normoxia with fresh medium. After the indicated time of incubation in hypoxic environment, cells were harvested and analyzed for the expression of both protein and mRNA for HIF-1 $\alpha$, COX-2, VEGF, MMP-2 and uPAR. For the invasion study siRNA transfected cells were trypsinized after $48 \mathrm{~h}$ of transfection and subjected to Matrigel invasion assay under hypoxia or normoxia. Sequence of HIF- $1 \alpha$ siRNA $\left(5^{\prime} \rightarrow 3^{\prime}\right)$ : Sense, GGGUAAAGAACAAAACA CAtt; anti-sense, UGUGUUUUGUUCUUUACCCtt purchased from Ambion, Inc, Austin, TX (Silencer ${ }^{\circledR}$ Validated siRNA ID\#: 42840). Silencer ${ }^{\circledR}$ Negative Control siRNA was also purchased from Ambion, Inc. and sequence is $\left(5^{\prime} \rightarrow 3^{\prime}\right)$ : sense, AGUACUGCUUACGAUACGGtt; anti-sense, CCGUAUCG UAAGCAGUACUtt.

Statistical analysis. All experiments were performed in triplicates. Results are expressed as means \pm standard deviation (SD). Statistical significance was determined by a Student's t-test with two tails and equal variances using Microsoft Excel and expressed as $\mathrm{p}<0.05$.

\section{Results}

SNS-032 inhibits hypoxia-mediated U87MG cell invasion. Glioblastomas have extensive area of hypoxia that plays a crucial role in invasiveness of these tumors (29). We have investigated the effect of SNS-032 on U87MG cell invasion in response to hypoxia. An invasion assay using BD Biocoat Matrigel invasion chamber was performed (Fig. 1). After incubation for 24 and $48 \mathrm{~h}$ in hypoxia or normoxia, the number of cells that penetrated through the Matrigel coated membrane was quantitated. Representative images are shown in Fig. 1A and the pooled results from three independent experiments are plotted in Fig. 1B. Invasiveness of U87MG cells incubated 
A

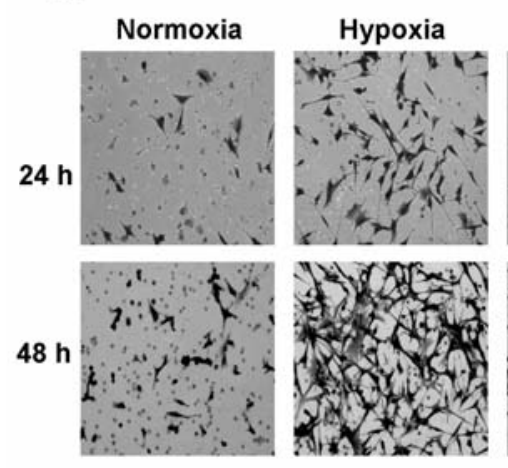

H+SNS-032

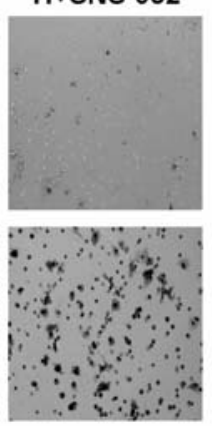

B

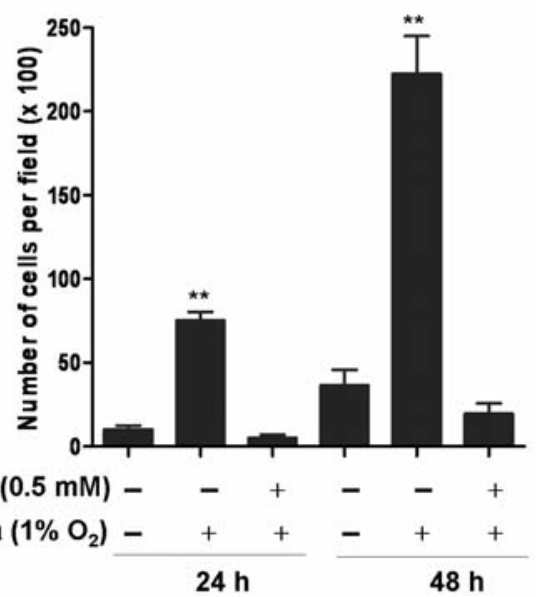

Figure 1. Effect of SNS-032 on U87MG cell invasion. Cells $\left(5 \times 10^{4}\right)$ were cultured into the insert of Matrigel invasion chamber (BD Bioscience) with or without SNS-032 $(0.5 \mu \mathrm{M})$ for $2 \mathrm{~h}$ and incubated under normoxic $\left(20 \% \mathrm{O}_{2}\right)$ or hypoxic $\left(1 \% \mathrm{O}_{2}\right)$ conditions for 24 and $48 \mathrm{~h}$. The assay was ran in duplicate and repeated three times. A, Representative images of U87MG cell invasion; B, Total number of invaded cells per field (x100); bars, SD calculated from three independent experiments; ${ }^{* *} \mathrm{p}<0.001$, significantly different from normoxia or hypoxia + SNS-032.

in hypoxia was increased more than 8 -fold at $24 \mathrm{~h}$ and 5.6 -fold at $48 \mathrm{~h}$ when compared to invasion under normoxia. Prior exposure of SNS-032 at $0.5 \mu \mathrm{M}$ for $2 \mathrm{~h}$ completely prevented the hypoxia-mediated invasion of U87MG cells at both timepoints (Fig. 1). This result showed that SNS-032 is highly effective in preventing hypoxia-induced invasion of U87MG cells.

SNS-032 inhibits hypoxia-mediated HIF-1a expression. Hypoxia-induced HIF-1 $\alpha$ protein is considered as a master transcription factor regulating multiple genes involved in tumor invasion and angiogenesis (8). In an attempt to verify the effect of SNS-032 on HIF-1 $\alpha$ expression in this cell line under hypoxic condition, cells were treated with SNS-032 $(0.5 \mu \mathrm{M})$ or vehicle for $2 \mathrm{~h}$ and then exposed to hypoxia for 24 and $48 \mathrm{~h}$. As expected, hypoxia increased HIF-1 $\alpha$ expression (Fig. 2A, lanes 2 and 5) whereas no induction was noted in normoxia (Fig. 2A, lanes 1 and 4). Prior incubation of cells with SNS-032, abolished hypoxia-induced HIF-1a expression (Fig. 2A, lanes 3 and 6). This result clearly indicates that SNS-032 inhibits hypoxia-induced HIF-1 $\alpha$ expression in this glioma cell line.

In hypoxia, HIF- $1 \alpha$ levels are significantly increased due to decreased proteasomal degradation resulting from the inactivation of HIF prolyl-hydroxylase under oxygen deprived conditions (4). To further investigate the effect of SNS-032 on HIF- $1 \alpha$ expression, U87MG cells were treated with a $26 \mathrm{~S}$ proteasome inhibitor MG132 in normoxic conditions. Immunoblot analysis of HIF- $1 \alpha$ demonstrated a significant level was detected after $18 \mathrm{~h}$ in normoxia (Fig. 2B, lane 2). We observed a similar level of HIF- $1 \alpha$ expression when cells were treated with MG-132 prior to the addition of SNS-032 (Fig. 2B, lane 4) indicating that SNS-032 was not associated with the ubiquitin-proteasome pathway of HIF-1 $\alpha$ degradation. In this condition, HIF- $1 \alpha$ expression was unchanged up to $18 \mathrm{~h}$ when SNS-032 was added to the cell culture medium $6 \mathrm{~h}$ after the addition of MG132 (Fig. 2B, lane 4). In contrast, we did not observe HIF-1 $\alpha$ expression in normoxia when the cells were preincubated with SNS-032 followed by the addition
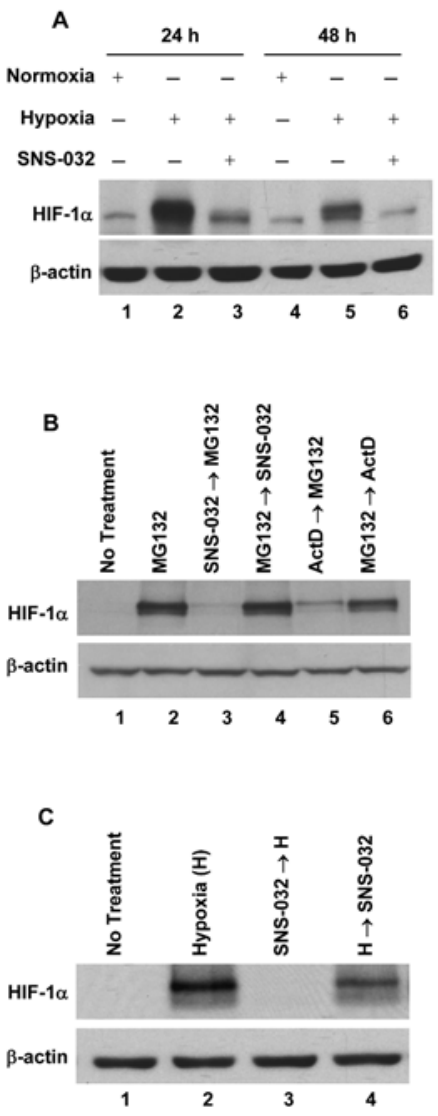

Figure 2. Effect of SNS-032 on hypoxia-induced HIF-1 $\alpha$ expression in U87MG cells. A, Immunoblot analysis of HIF-1 $\alpha$. U87MG glioblastoma cells were pretreated with SNS-032 $(0.5 \mu \mathrm{M})$ for $2 \mathrm{~h}$ and then incubated under normoxic and hypoxic condition for 24 and 48 h. B, Effects of SNS-032, proteasome inhibitor M132, and transcriptional inhibitor actinomycin D on HIF-1 $\alpha$ expression. Cells were treated as follows: lane 1, untreated (normoxia); lane 2, MG132, $18 \mathrm{~h}$; lane 3, SNS-032, $6 \mathrm{~h} \rightarrow \mathrm{MG} 132,12 \mathrm{~h}$; lane 4, MG132, $6 \mathrm{~h} \rightarrow$ SNS-032, $12 \mathrm{~h}$; lane 5, ActD, $6 \mathrm{~h} \rightarrow \mathrm{MG} 132,12 \mathrm{~h}$; and lane 6, MG132, $6 \mathrm{~h} \rightarrow$ ActD, $12 \mathrm{~h}$. Concentration used, SNS-032 $(0.5 \mu \mathrm{M}), \mathrm{MG} 132(1 \mu \mathrm{M})$ and ActD $(2 \mu \mathrm{g} / \mathrm{ml})$. HIF-1 $\alpha$ expression was analyzed by immunoblot analysis. $\mathrm{C}$, Effects on hypoxic accumulation of HIF-1 $\alpha$. Lane 1, untreated (normoxia); lane 2 , hypoxia for $24 \mathrm{~h}$; lane 3, SNS-032 (6 h) $\rightarrow$ hypoxia $(18 \mathrm{~h})$; lane 4, hypoxia $(6 \mathrm{~h}) \rightarrow$ SNS-032 (18 h). HIF-1 $\alpha$ expression was analyzed by immunoblot analysis. B-actin immunoblot was performed for the loading control. 
A

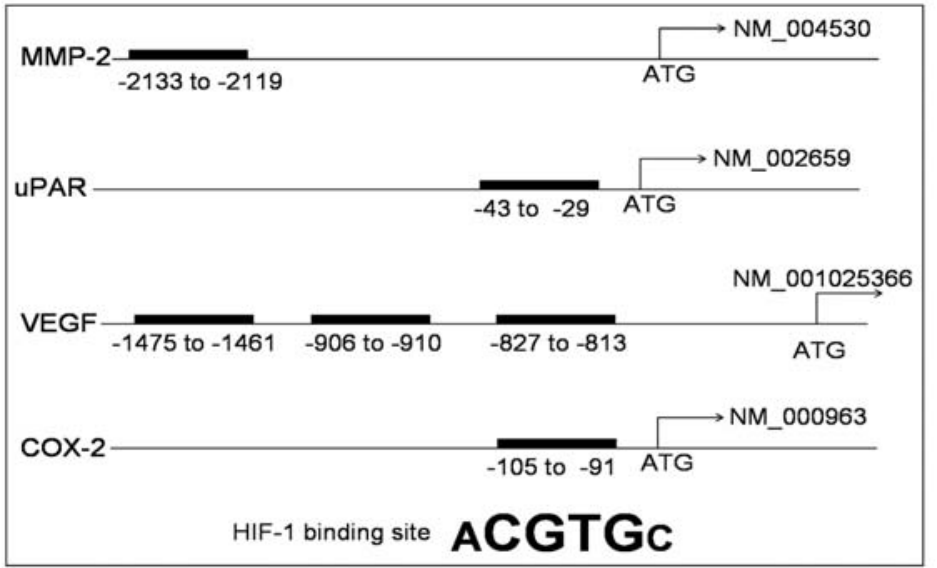

B

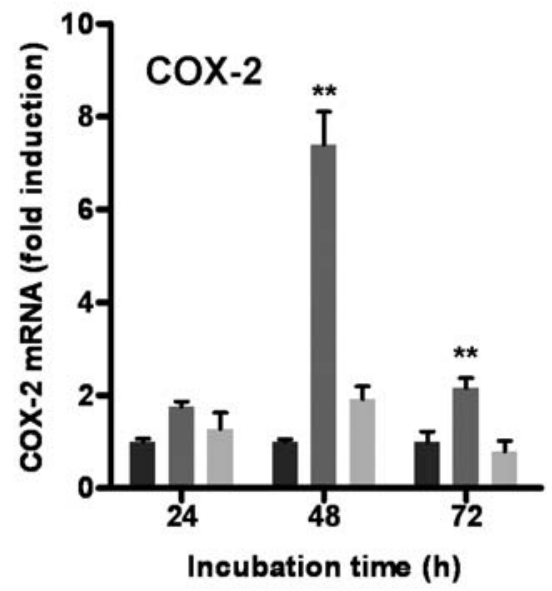

Normoxia Hypoxia Hypoxia+SNS-032
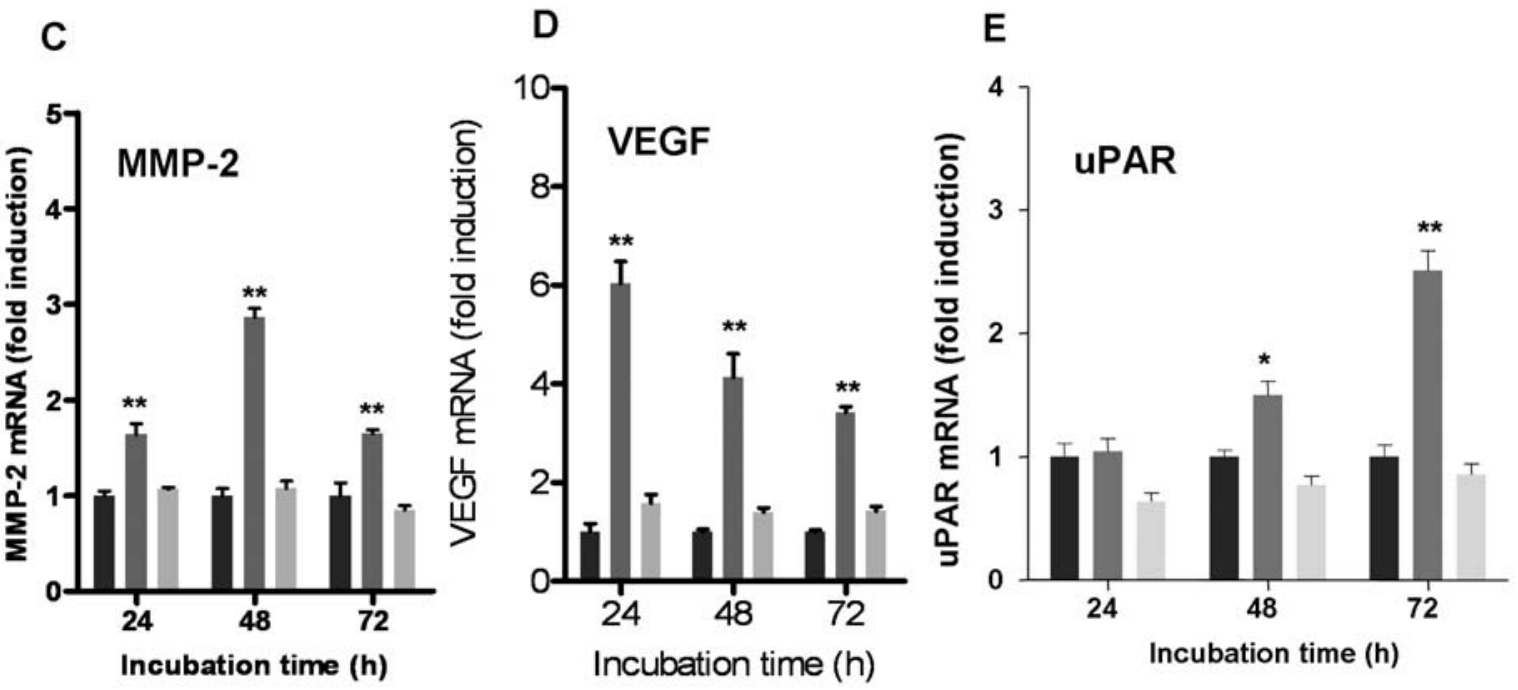

Figure 3. A, HIF-1 $\alpha$ binding site(s) with consensus core sequence (ACGTGC) in the promoter region of several hypoxia-induced genes. The coordinates of HIF- $1 \alpha$ binding sites were calculated with respect to the start codon (ATG, considered as position +1 ). Effect of SNS-032 on hypoxia-induced mRNA expression of COX-2 (B), MMP-2 (C), VEGF (D) and UPAR (E) in U87MG cells. Cells were pretreated with SNS-032 (0.5 $\mu$ M) for 2 h and then incubated under normoxia or hypoxia for the indicated time-intervals. Total RNA was extracted and mRNAs were analyzed by quantitative real-time reverse transcription-PCR (RT-PCR) using SYBR Green PCR Master Mix. Primer sequences used for this experiment are shown in Table I. Bars, SD. (n=3); ${ }^{*}<0.05$; and ${ }^{* *} \mathrm{p}<0.001$ compared with normoxia or hypoxia + SNS-032.

of MG132 (Fig. 2B, lanes 1 and 3) further indicating that it inhibited gene transcription. This observation was consistent with the result obtained from the following experiment using actinomycin D (ActD), a chemical blocker of gene transcription (Fig. 2B, lanes 5 and 6)

Next, we analyzed whether SNS-032 acts similarly on hypoxic accumulation of HIF-1 $\alpha$. Cells were pretreated with SNS-032 for $6 \mathrm{~h}$ and exposed to hypoxia for another $18 \mathrm{~h}$, and oppositely SNS-032 was added $6 \mathrm{~h}$ after exposure to hypoxia and the cells were maintained in hypoxia for a further $18 \mathrm{~h}$. These results show that a substantial induction HIF-1 $\alpha$ expression is observed in response to hypoxia (Fig. 2C, lane 2), but is completely inhibited when cells were pretreated with SNS-032 (Fig. 2C, lane 3). However, treatment of cells with SNS-032 after $6 \mathrm{~h}$ of hypoxia did not inhibit hypoxic induction of HIF-1 $\alpha$ (Fig. 2C, lane 4).
SNS-032 inhibits hypoxia-mediated COX-2, MMP-2, uPAR and VEGF gene expression. As mentioned earlier HIF-1 $\alpha$ induces transcription of key regulatory proteins such as COX-2, VEGF, MMP-2 and UPAR that are involved in aggressive invasion often seen in GBM $(14,19,24,30,31)$. The presence of HIF-1 $\alpha$ binding site(s) with consensus core sequence (ACGTGC) in the promoter region of these hypoxia-induced genes is shown in Fig. 3A and were searched by using the software MATCH 11.2 (biobase-international) (32). We observed a robust inhibition of U87MG glioma cell invasion in response to hypoxia (Fig. 1). To investigate whether SNS-032 can prevent the expressions of these proteins, we examined their mRNA expression by real-time RT-PCR using the primers as listed in Table I. U87MG cells were pretreated with SNS-032 for $2 \mathrm{~h}$ and then exposed to hypoxia for 24,48 and $72 \mathrm{~h}$. Hypoxia led to the upregulation of 

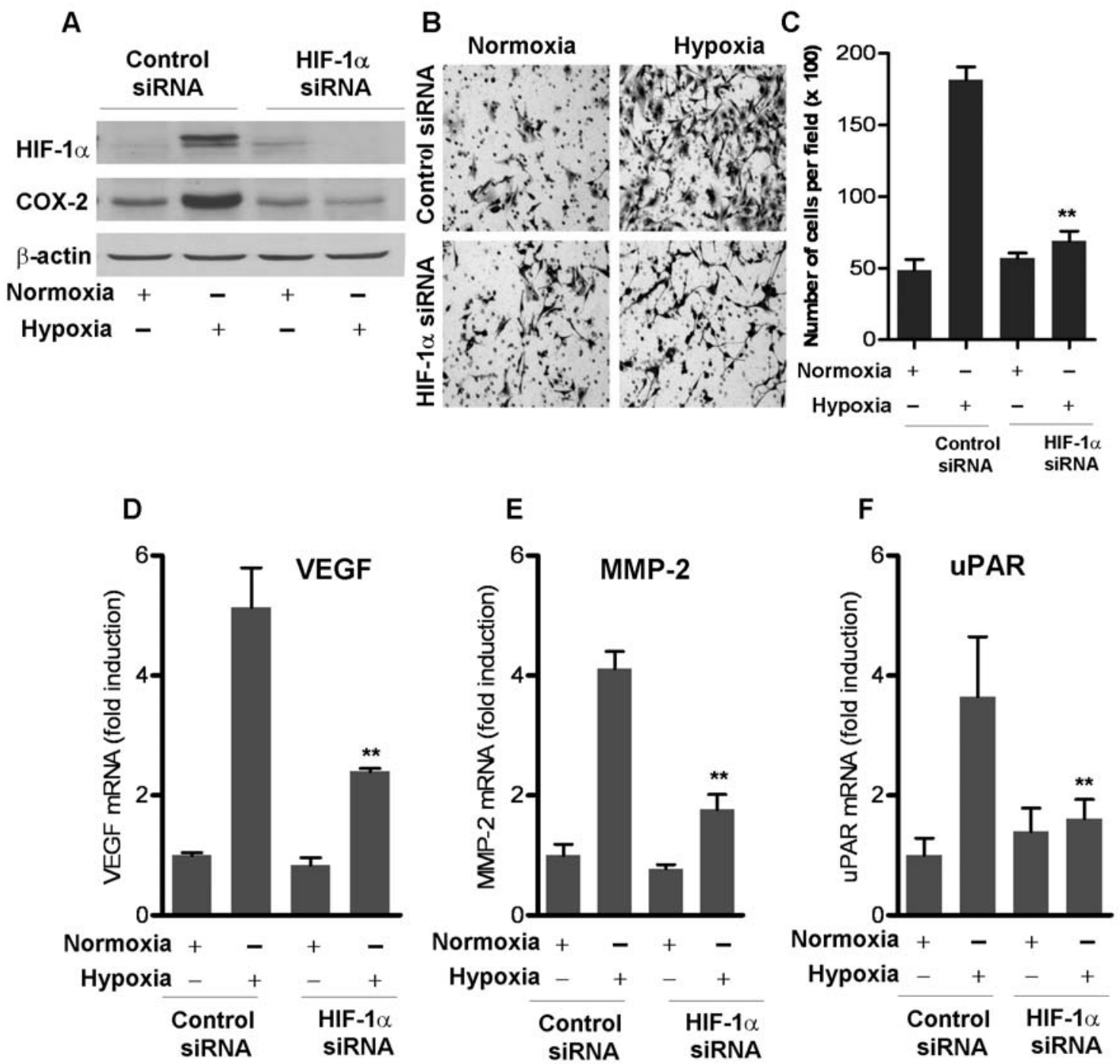

Figure 4. HIF-1 $\alpha$ siRNA prevents hypoxic induction of HIF-1 $\alpha$, COX-2, MMP-2, uPAR and VEGF expression in U87MG cells. A, HIF-1 $\alpha$ and COX-2 expression by immunoblot analysis. U87MG cells were transfected with control siRNA or HIF-1 $\alpha$ siRNA $(0.1 \mu \mathrm{M})$ as indicated. After $48 \mathrm{~h}$ of transfection, cells were exposed to either normoxic or hypoxic condition for further $48 \mathrm{~h}$. Cells were harvested and subjected to immunoblot analysis for HIF-1 $\alpha$ and COX-2. $\mathrm{B}$ and $\mathrm{C}, \mathrm{HIF}-1 \alpha$ siRNA prevented hypoxic induction of U87MG cell invasion. U87MG cells were transfected with HIF-1 $\alpha$ siRNA or a control siRNA as before and subjected to invasion assay under normoxic or hypoxic conditions for $48 \mathrm{~h}$. B, Representative images of U87MG cell invasion; C, Total number of invaded cells per field (x100) was measured; bars, SD calculated from three independent experiments; ${ }^{* *}$ p $<0.001$, significantly different from control siRNA-transfected hypoxic cells (bar 2 vs bar 4). D-F, mRNA analysis of VEGF, MMP-2 and uPAR in response to hypoxia in the HIF-1 $\alpha$ or control siRNA transfected U87MG cells. Experimental conditions were similar as described in A. Bars, SD calculated from three independent experiments; ${ }^{* *}$ p<0.001 compared with control siRNA transfected hypoxic cells (bar 2 vs bar 4).

mRNA levels of COX-2, VEGF, MMP-2 and uPAR. In the case of COX-2, a marked increase of mRNA was noted at $48 \mathrm{~h}$ and was almost completely inhibited by SNS-032 (Fig. 3B). We also performed an immunoblot analysis of COX-2 expression and ELISA for COX-2 activity at these time-points (data not shown) and our results are consistent with the RT-PCR analysis. A similar pattern was observed with MMP-2 (Fig. 3C). We noted a significant induction of VEGF mRNA at $24 \mathrm{~h}$ after induction of hypoxia that gradually decreased with time. SNS-032 was effective in preventing the transcription of VEGF at all time-points (Fig. 3D). uPAR induction was increased over time and was highest after 72 h (Fig. 3E) under hypoxia. Again, complete inhibition of induction was achieved in the presence of SNS-032. These results suggest that SNS-032 is preventing the transcription of important proteins that are necessary for glioma cell invasion in hypoxia.

HIF-1a siRNA blocks hypoxia-induced U87MG cell invasion and abrogates COX-2, VEGF, MMP-2 and UPAR expression. To verify the role of HIF- $1 \alpha$ in the induction of these key proteins and glioma cell invasion, we transfected U87MG cells with HIF-1 $\alpha$ siRNA and performed: i) invasion assay, ii) mRNA analysis of VEGF, MMP-2 and UPAR by real-time PCR. Data presented in Fig. 4 show that the protein expression of HIF- $1 \alpha$ is abrogated by the transfection of HIF- $1 \alpha$ siRNA at $0.1 \mu \mathrm{M}$ concentration, whereas levels of HIF-1 $\alpha$ protein remained unchanged when cells were transfected with same concentration $(0.1 \mu \mathrm{M})$ of negative control siRNA (Fig. 4A, top panel). Same membrane was then probed for COX-2 

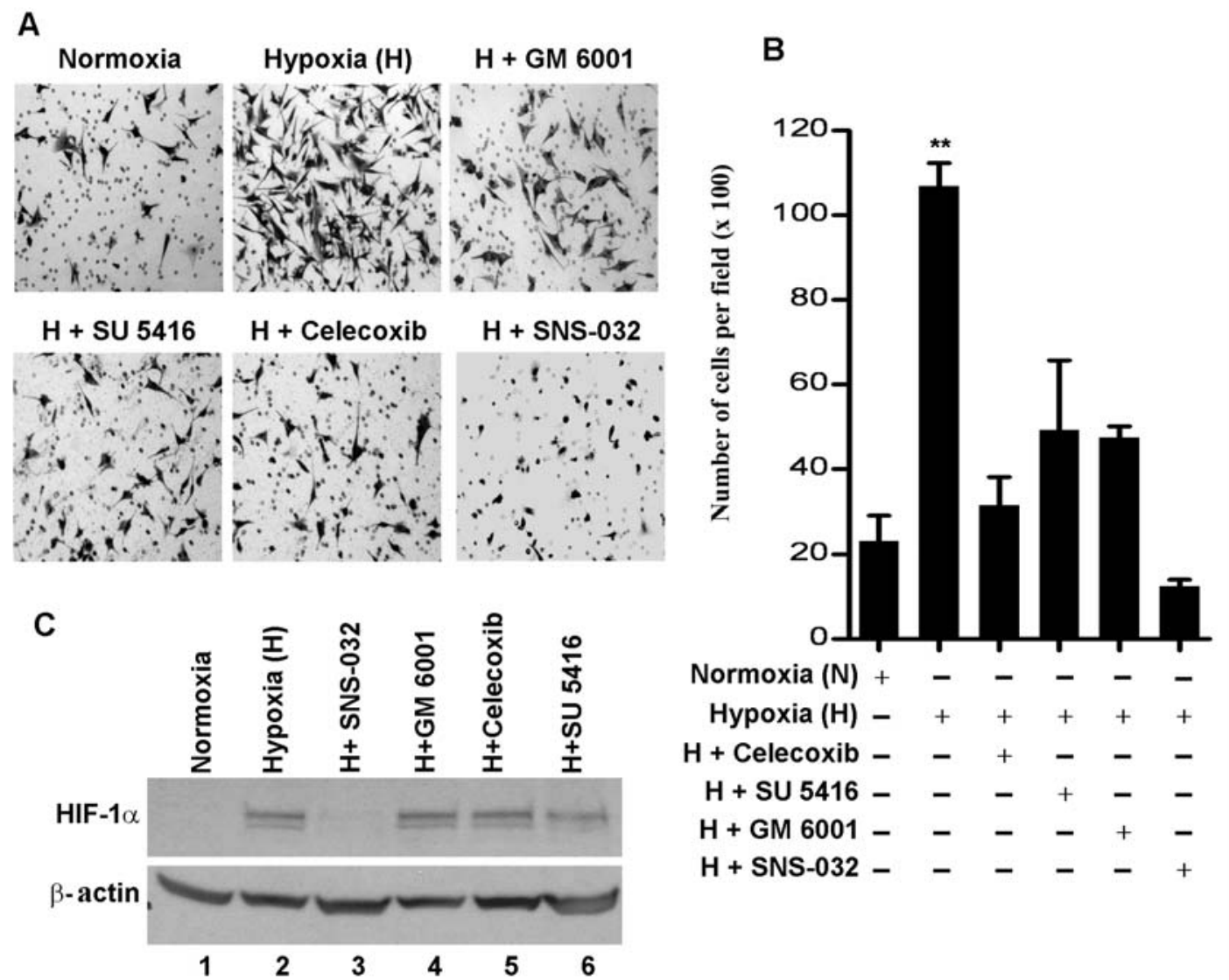

Figure 5. Effect of COX-2, VEGF and MMP-2 inhibitors on U87MG cell invasion. Cells (5x104) were plated into the insert of Matrigel invasion chamber with or without inhibitors (celecoxib, $10 \mu \mathrm{M}$ for COX-2, SU 5416, $10 \mu \mathrm{M}$ for VEGFR and GM 6001, 30 $\mu \mathrm{M}$ for MMP-2) and incubated under normoxic or hypoxic conditions for $48 \mathrm{~h}$. A, Representative images of U87MG cell invasion; B, Total number of invaded cells per field (x100) was measured; bars, SD calculated from three independent experiments; ${ }^{* *} \mathrm{p}<0.001$, significantly different from normoxia or hypoxia + inhibitor. C, Immunoblot analysis of HIF-1 $\alpha$ in U87MG cells under similar treatment conditions performed in invasion study using the inhibitors as indicated above.

expression. We found marked inhibition of COX-2 expression in HIF-1 $\alpha$ siRNA transfected cells under hypoxia (Fig. 4A, middle panel). On the other hand a steady induction of COX-2 expression was noted in the negative control siRNA transfected cells under hypoxic condition (Fig. 4A, middle panel). In the next experiment, HIF-1 $\alpha$ or control siRNA transfected cells were exposed to hypoxia or normoxia as indicated for $48 \mathrm{~h}$ and invasion assay was performed. Silencing of HIF-1 $\alpha$ expression resulted in a striking inhibition of hypoxia-induced cellular invasion. Representative images are shown in Fig. 4B and the pooled results from three independent experiments are plotted in Fig. 4C. Under similar conditions, cells were harvested for total RNA isolation and subjected to real-time PCR analysis. We observed that cells transfected with HIF-1 $\alpha$ siRNA showed modest (VEGF and MMP-2, Fig. 4D and E) or no induction (uPAR) under hypoxia (Fig. 4F). These results clearly indicate that the HIF- $1 \alpha$ substantially contributes to glioblastoma cell invasion specifically in a hypoxic environment. SNS-032 mediated inhibition of U87MG cell invasion was therefore, due to the blocking of HIF-1 $\alpha$ and HIF-1 $\alpha$ mediated induction of these key factors.

Effect of COX-2, VEGF and MMP-2 inhibitors in U87MG cell invasion. COX-2, VEGF and MMP-2 are overexpressed in many cancers and these genes are transcriptionally up- regulated by HIF-1 $1 \alpha(9,12,33)$. In this experiment we compared the efficacy of SNS-032 with known inhibitors of COX-2, VEGF and MMP-2 in preventing the U87MG cell invasion in response to hypoxia. We performed an invasion assay, in the presence of celecoxib (COX-2 inhibitor), SU 5416 (VEGF-RII inhibitor) and GM 6001 (MMP inhibitor) along with SNS-032. The results presented in Fig. 5 demonstrate that celecoxib, SU 5416 and GM 6001 significantly inhibited hypoxia-mediated invasion of U87MG cells (Fig. 5A and B). However, the most prominent effect was observed when SNS-032 was used and this action is attributable to the blocking of HIF-1 $\alpha$. We showed by an immunoblot analysis that none of these inhibitors are able to prevent the induction of HIF-1 $\alpha$ under hypoxic condition except SNS-032 (Fig. 5C). Our results demonstrated that SNS032 at $0.5 \mu \mathrm{M}$ concentration is highly effective when compared with the other inhibitors that were used at a higher dosage $(10 \mu \mathrm{M})$.

\section{Discussion}

Tumor cell invasion is a complex multi-step process associated with increased cell motility and lysis of the extracellular matrix (ECM). In this study we have investigated four critical proteins (COX-2, VEGF, MMP-2 and UPAR) that are actively 
involved in this process and regulated by HIF-1 $\alpha$ under hypoxic condition. COX-2 levels are frequently elevated in high-grade gliomas. This expression has been associated with their aggressive growth characteristics and poor prognosis for patients $(34,35)$. Selective inhibition of COX-2 by NS-398 (a selective COX-2 inhibitor) in human gliomas in two different in vitro models reduces growth activity $(36,37)$. COX-2 is also elevated in response to hypoxia, it has been reported that HIF- $1 \alpha$ interacts with the HIF responsive elements (HRE) in the COX-2 promoter, thereby inducing its expression (38). Previously, we reported SNS-032 blocked cytokine meditated induction of COX-2 expression (39). In this study we found SNS-032 is highly effective in preventing the hypoxia-induced COX-2 mRNA (Fig. 3B) as well as protein expression (data not shown) in U87MG cells. We noticed that celecoxib, a selective inhibitor of COX-2, blocked the invasion of U87MG cells (Fig. 5A and B). Hypoxia-induced VEGF plays a critical role in the various stages of invasion and metastasis in human glioma cells (40). Up-regulation of VEGF occurs via multiple hypoxia-inducible mechanisms including increased expression and stabilization of VEGF mRNA. The VEGF promoter contains multiple HRE (Fig. 3A) indicating that hypoxia-induced expression of VEGF is HIF-dependent (41). There are several mechanisms describing the role of VEGF in glioma cell invasion under hypoxia. Zagzag et al, showed that VEGF up-regulated CXCR4 in a HIF-dependent manner and contributes to cell invasion and angiogenesis (25). In addition, tumor cells can acquire these invasive properties by the production and secretion of several proteases. MMPs are the largest group of ECM-degrading enzymes contributing to the aggressive invasive features of many cancer types and hypoxia plays an important role in the upregulation of multiple MMPs including MMP-2. Up-regulated expression of MMP-2 was found in the invasive regions of primary human glioma specimens and in intracranial xenografts of U87MG glioma cells $(42,43)$. SNS-032 was effective in preventing the hypoxia-induced MMP-2 up-regulation (Fig. 3C) and a panmetalloproteinase inhibitor GM 6001 (44) was used in this study that significantly blocked the hypoxia-induced invasion of U87MG cells (Fig. 5A and B). Up-regulation of UPAR in hypoxia enhances the proteolytic activity and inhibits the interactions between integrins and ECM at the invasive front of the tumor mass, thereby enabling cellular invasion through the basement membrane $(45,46)$. Inhibition of uPAR expression by antisense oligonucleotides in glioblastoma cells results in prevention of tumor formation in nude mice (45). A recent study using UPAR RNAi demonstrated the inhibition of invasion, cell migration and also regression of intracranial tumor in mouse model (47). uPAR level was also reported to be induced by HIF-1 $\alpha$ in hypoxic environment $(48,49)$ In this study, we showed that a HIF-1 $\alpha$ binding element is present in the promoter of uPAR (Fig. 3A) and its activation in hypoxic condition is blocked by SNS032 (Fig. 3E).

Small molecule Cdk inhibitors demonstrated change in wide range of gene expression. In general Cdk-inhibitors demonstrate transcriptional down-regulation largely due to the decrease in transcription factor expression. This is due to the inhibition of C-terminal Ser/Thr phosphorylation of RNA polymerase II. Interestingly, Lu et al reported that a cluster of gene expressions is induced in response to such small molecule Cdk inhibitors (50).

In the last ten years significant progress has been achieved in exploring the role of HIF-1 $\alpha$ in the field of cancer biology. Hypoxia was demonstrated to be present in almost any macroscopic solid tumor and to be associated with decreased response rates to anti-cancer agents used in clinical oncology. Presence of hypoxic cells was shown to be associated with tumor progression, enhanced metastatic potential, poor prognosis and therapy resistance (51-54). It was reported that hypoxic cells are three times more resistant to ionizing radiation compared to well-oxygenated cells (55). Often these observed effects are linked to the up-regulation of this master transcription factor HIF-1 $\alpha$ (8). It is highly important to identify substances that can regulate the expression and activity of HIF- $1 \alpha$ and have the potential to improve the efficiency of clinical treatment. Several compounds are now reported that can prevent HIF- $1 \alpha$ and HIF- $1 \alpha$-mediated signaling in cancer cells. Two marine biological compounds demonstrated to inhibit HIF- $1 \alpha$ and VEGF in breast tumor cells $(56,57)$. Flavopiridol, a pan-cdk inhibitor and Noscapine also prevented HIF-1 $\alpha$ expression in glioma cells (6). The pilot screen program of National Cancer Institute identified several compounds that are structurally related to camptothecin and topoisomerase (Topo)-I inhibitors abrogated HIF$1 \alpha$ activity in U251 cells $(58,59)$. In this study, we reported that the novel CDK 2, 7 and 9 inhibitor SNS-032 is highly effective in preventing hypoxia-induced HIF-1 $\alpha$ and invasion of glioma cells. Taken together, SNS-032 might be an effective agent to increase the therapeutic benefit against this deadly disease.

\section{Acknowledgements}

This work was supported by the Flight Attendant Medical Research Institute Young Clinical Scientist Award (D.S.).

\section{References}

1. Brat DJ, Castellano-Sanchez AA, Hunter SB, et al: Pseudopalisades in glioblastoma are hypoxic, express extracellular matrix proteases, and are formed by an actively migrating cell population. Cancer Res 64: 920-927, 2004.

2. Fischer I, Gagner JP, Law M, Newcomb EW and Zagzag D: Angiogenesis in gliomas: biology and molecular pathophysiology. Brain Pathol 15: 297-310, 2005.

3. Fujiwara S, Nakagawa K, Harada $\mathrm{H}$, et al: Silencing hypoxiainducible factor-1alpha inhibits cell migration and invasion under hypoxic environment in malignant gliomas. Int J Oncol 30: 793-802, 2007.

4. Kaur B, Khwaja FW, Severson EA, Matheny SL, Brat DJ and van Meir EG: Hypoxia and the hypoxia-inducible-factor pathway in glioma growth and angiogenesis. Neurooncology 7: 134-153, 2005.

5. Liao D and Johnson RS: Hypoxia: a key regulator of angiogenesis in cancer. Cancer Metastasis Rev 26: 281-290, 2007.

6. Newcomb EW, Ali MA, Schnee T, et al: Flavopiridol downregulates hypoxia-mediated hypoxia-inducible factor-1alpha expression in human glioma cells by a proteasome-independent pathway: implications for in vivo therapy. Neurooncology 7: 225-235, 2005.

7. Zheng X, Jiang F, Katakowski M, et al: Inhibition of ADAM17 reduces hypoxia-induced brain tumor cell invasiveness. Cancer Sci 98: 674-684, 2007.

8. Semenza GL: Targeting HIF-1 for cancer therapy. Nat Rev Cancer 3: 721-732, 2003. 
9. Kaidi A, Qualtrough D, Williams AC and Paraskeva C: Direct transcriptional up-regulation of cyclooxygenase- 2 by hypoxiainducible factor (HIF)-1 promotes colorectal tumor cell survival and enhances HIF-1 transcriptional activity during hypoxia. Cancer Res 66: 6683-6691, 2006

10. Singh B, Berry JA, Shoher A, Ramakrishnan V and Lucci A: COX-2 overexpression increases motility and invasion of breast cancer cells. Int J Oncol 26: 1393-1399, 2005.

11. Nilsson I, Shibuya M and Wennstrom S: Differential activation of vascular genes by hypoxia in primary endothelial cells. Exp Cell Res 299: 476-485, 2004.

12. Krishnamachary B, Berg-Dixon S, Kelly B, et al: Regulation of colon carcinoma cell invasion by hypoxia-inducible factor 1 . Cancer Res 63: 1138-1143, 2003.

13. Munoz-Najar UM, Neurath KM, Vumbaca F and Claffey KP: Hypoxia stimulates breast carcinoma cell invasion through MT1MMP and MMP-2 activation. Oncogene 25: 2379-2392, 2006.

14. Gondi CS, Lakka SS, Dinh DH, Olivero WC, Gujrati M and Rao JS: Downregulation of uPA, uPAR and MMP-9 using small, interfering, hairpin RNA (siRNA) inhibits glioma cell invasion, angiogenesis and tumor growth. Neuron Glia Biol 1 : 165-176, 2004.

15. Giese A and Westphal M: Glioma invasion in the central nervous system. Neurosurgery 39: 232-250, 1996.

16. Chintala SK, Tonn JC and Rao JS: Matrix metalloproteinases and their biological function in human gliomas. Int $\mathrm{J}$ Dev Neurosci 17: 495-502, 1999.

17. Yong VW, Power C, Forsyth P and Edwards DR: Metalloproteinases in biology and pathology of the nervous system. Nat Rev Neurosci 2: 502-511, 2001.

18. Yamamoto M, Sawaya R, Mohanam S, et al: Expression and localization of urokinase-type plasminogen activator in human astrocytomas in vivo. Cancer Res 54: 3656-3661, 1994

19. Larkins TL, Nowell M, Singh S and Sanford GL: Inhibition of cyclooxygenase-2 decreases breast cancer cell motility, invasion and matrix metalloproteinase expression. BMC Cancer 6: 181, 2006.

20. Byun JH, Lee MA, Roh SY, et al: Association between cyclooxygenase- 2 and matrix metalloproteinase- 2 expression in non-small cell lung cancer. Jpn J Clin Oncol 36: 263-268, 2006

21. Buchanan FG, Wang D, Bargiacchi F and DuBois RN: Prostaglandin E2 regulates cell migration via the intracellular activation of the epidermal growth factor receptor. J Biol Chem 278: 35451-35457, 2003

22. Pai R, Nakamura T, Moon WS and Tarnawski AS: Prostaglandins promote colon cancer cell invasion; signaling by cross-talk between two distinct growth factor receptors. FASEB J 17: 1640-1647, 2003.

23. Ali MA, Choy H, Habib AA and Saha D: SNS-032 prevents tumor cell-induced angiogenesis by inhibiting vascular endothelial growth factor. Neoplasia 9: 370-381, 2007.

24. Carmeliet P: VEGF as a key mediator of angiogenesis in cancer. Oncology 69 (Suppl. 3): 4-10, 2005.

25. Zagzag D, Lukyanov Y, Lan L, et al: Hypoxia-inducible factor 1 and VEGF upregulate CXCR4 in glioblastoma: implications for angiogenesis and glioma cell invasion. Lab Invest 86: 1221-1232, 2006

26. Senderowicz AM: Cyclin-dependent kinases as targets for cancer therapy. Cancer Chemother Biol Response Modif 20: 169-196, 2002.

27. Shapiro GI: Cyclin-dependent kinase pathways as targets for cancer treatment. J Clin Oncol 24: 1770-1783, 2006.

28. Swanton C: Cell-cycle targeted therapies. Lancet Oncol 5: 27-36, 2004.

29. Giese A, Bjerkvig R, Berens ME and Westphal M: Cost of migration: invasion of malignant gliomas and implications for treatment. J Clin Oncol 21: 1624-1636, 2003.

30. Vaupel P: The role of hypoxia-induced factors in tumor progression. Oncologist 9 (Suppl. 5): 10-17, 2004.

31. Deryugina EI, Luo GX, Reisfeld RA, Bourdon MA and Strongin A: Tumor cell invasion through matrigel is regulated by activated matrix metalloproteinase-2. Anticancer Res 17: 3201-3210, 1997.

32. Kel AE, Gossling E, Reuter I, Cheremushkin E, KelMargoulis OV and Wingender E: MATCH: a tool for searching transcription factor binding sites in DNA sequences. Nucleic Acids Res 31: 3576-3579, 2003.
33. Gerber HP, Condorelli F, Park J and Ferrara N: Differential transcriptional regulation of the two vascular endothelial growth factor receptor genes. Flt-1, but not Flk-1/KDR, is up-regulated by hypoxia. J Biol Chem 272: 23659-23667, 1997.

34. Bijnsdorp IV, van den Berg J, Kuipers GK, et al: Radiosensitizing potential of the selective cyclooygenase-2 (COX-2) inhibitor meloxicam on human glioma cells. J Neurooncol 85: 25-31, 2007.

35. Shono T, Tofilon PJ, Bruner JM, Owolabi O and Lang FF: Cyclooxygenase-2 expression in human gliomas: prognostic significance and molecular correlations. Cancer Res 61: 4375-4381, 2001

36. Deininger MH, Weller M, Streffer J, Mittelbronn M and Meyermann R: Patterns of cyclooxygenase-1 and -2 expression in human gliomas in vivo. Acta Neuropathol 98: 240-244, 1999.

37. Joki T, Heese O, Nikas DC, et al: Expression of cyclooxygenase $2(\mathrm{COX}-2)$ in human glioma and in vitro inhibition by a specific COX-2 inhibitor, NS-398. Cancer Res 60: 4926-4931, 2000.

38. Csiki I, Yanagisawa K, Haruki N, et al: Thioredoxin-1 modulates transcription of cyclooxygenase-2 via hypoxia-inducible factor1alpha in non-small cell lung cancer. Cancer Res 66: 143-150, 2006.

39. Mukhopadhyay P, Ali MA, Nandi A, Carreon P, Choy H and Saha D: The cyclin-dependent kinase 2 inhibitor down-regulates interleukin-1beta-mediated induction of cyclooxygenase- 2 expression in human lung carcinoma cells. Cancer Res 66: $1758-1766,2006$

40. Shweiki D, Itin A, Soffer D and Keshet E: Vascular endothelial growth factor induced by hypoxia may mediate hypoxiainitiated angiogenesis. Nature 359: 843-845, 1992.

41. Forsythe JA, Jiang BH, Iyer NV, et al: Activation of vascular endothelial growth factor gene transcription by hypoxia-inducible factor 1. Mol Cell Biol 16: 4604-4613, 1996.

42. Guo P, Imanishi Y, Cackowski FC, et al: Up-regulation of angiopoietin-2, matrix metalloprotease-2, membrane type 1 metalloprotease, and laminin 5 gamma 2 correlates with the invasiveness of human glioma. Am J Pathol 166: 877-890, 2005.

43. Wang M, Yoshida D, Liu S and Teramoto A: Inhibition of cell invasion by indomethacin on glioma cell lines: in vitro study. J Neurooncol 72: 1-9, 2005.

44. Nakamura JL, Haas-Kogan DA and Pieper RO: Glioma invasiveness responds variably to irradiation in a co-culture model. Int J Rad Oncol Biol Phys 69: 880-886, 2007.

45. Puli S, Lai JC and Bhushan A: Inhibition of matrix degrading enzymes and invasion in human glioblastoma (U87MG) cells by isoflavones. J Neurooncol 79: 135-142, 2006.

46. Sullivan R and Graham CH: Hypoxia-driven selection of the metastatic phenotype. Cancer Metastasis Rev 26: 319-331, 2007.

47. Gondi CS, Lakka SS, Dinh DH, Olivero WC, Gujrati M and Rao JS: Intraperitoneal injection of a hairpin RNA-expressing plasmid targeting urokinase-type plasminogen activator (uPA) receptor and $\mathrm{UPA}$ retards angiogenesis and inhibits intracranial tumor growth in nude mice. Clin Cancer Res 13: 4051-4060, 2007.

48. Shyu KG, Hsu FL, Wang MJ, Wang BW and Lin S: Hypoxiainducible factor 1alpha regulates lung adenocarcinoma cell invasion. Exp Cell Res 313: 1181-1191, 2007.

49. Sprague LD, Tomaso H, Mengele K, et al: Effects of hypoxia and reoxygenation on the expression levels of the urokinasetype plasminogen activator, its inhibitor plasminogen activator inhibitor type-1 and the urokinase-type plasminogen activator receptor in human head and neck tumour cells. Oncol Rep 17: 1259-1268, 2007

50. Lu X, Burgan WE, Cerra MA, et al: Transcriptional signature of flavopiridol-induced tumor cell death. Mol Cancer Ther 3: $861-872,2004$

51. Brennan DJ, Jirstrom K, Kronblad A, et al: CA IX is an independent prognostic marker in premenopausal breast cancer patients with one to three positive lymph nodes and a putative marker of radiation resistance. Clin Cancer Res 12: 6421-6431, 2006.

52. Fyles A, Milosevic M, Hedley D, et al: Tumor hypoxia has independent predictor impact only in patients with node-negative cervix cancer. J Clin Oncol 20: 680-687, 2002. 
53. Movsas B, Chapman JD, Hanlon AL, et al: Hypoxic prostate/ muscle $\mathrm{pO} 2$ ratio predicts for biochemical failure in patients with prostate cancer: preliminary findings. Urology 60: 634-639, 2002.

54. Thomlinson RH and Gray LH: The histological structure of some human lung cancers and the possible implications for radiotherapy. Br J Cancer 9: 539-549, 1955

55. Gray LH, Conger AD, Ebert M, Hornsey S and Scott OC: The concentration of oxygen dissolved in tissues at the time of irradiation as a factor in radiotherapy. Br J Radiol 26: 638-648, 1953

56. Hodges TW, Hossain CF, Kim YP, Zhou YD and Nagle DG: Molecular-targeted antitumor agents: the Saururus cernuus dineolignans manassantin B and 4-O-demethylmanassantin B are potent inhibitors of hypoxia-activated HIF-1. J Nat Prod 67: 767-771, 2004.
57. Mohammed KA, Hossain CF, Zhang L, Bruick RK, Zhou YD and Nagle DG: Laurenditerpenol, a new diterpene from the tropical marine alga Laurenciaintricata that potently inhibits HIF-1 mediated hypoxic signaling in breast tumor cells. J Nat Prod 67: 2002-2007, 2004

58. Rapisarda A, Uranchimeg B, Scudiero DA, et al: Identification of small molecule inhibitors of hypoxia-inducible factor 1 transcriptional activation pathway. Cancer Res 62: 4316-4324, 2002.

59. Chau NM, Rogers P, Aherne W, et al: Identification of novel small molecule inhibitors of hypoxia-inducible factor- 1 that differentially block hypoxia-inducible factor- 1 activity and hypoxia-inducible factor-1alpha induction in response to hypoxic stress and growth factors. Cancer Res 65: 4918-4928, 2005. 